Communication et organisation

35 | 2009

Repenser la communication dans les organisations publiques

Christian Leray - L'analyse de contenu. De la théorie à la pratique - La méthode Morin-Chartier

Presses de l'Université du Québec, 180 p.

\title{
Benoît Cordelier
}

\section{OpenEdition}

\section{Journals}

Édition électronique

URL : http://journals.openedition.org/communicationorganisation/870

DOI : 10.4000/communicationorganisation. 870

ISSN : $1775-3546$

\section{Éditeur}

Presses universitaires de Bordeaux

\section{Édition imprimée}

Date de publication : 1 juin 2009

Pagination : 266

ISSN : $1168-5549$

\section{Référence électronique}

Benoît Cordelier, « Christian Leray - L'analyse de contenu. De la théorie à la pratique - La méthode Morin-Chartier », Communication et organisation [En ligne], 35 | 2009, mis en ligne le 10 mars 2011, consulté le 21 septembre 2020. URL : http://journals.openedition.org/communicationorganisation/ 870 ; DOI : https://doi.org/10.4000/communicationorganisation.870 


\section{Bibliographie}

\section{Christian Leray - L'analyse de contenu.}

De la théorie à la pratique - La méthode Morin-Chartier

Presses de l'Université du Québec, 180 p.

Christian Leray, ancien co-directeur du Laboratoire d'analyse de presse de l'Université du Québec à Montréal, partage dans son livre une expertise en analyse de contenu basée sur la méthode Morin-Chartier et développée auprès de grandes entreprises canadiennes (Mouvement Desjardins, Statistique Canada, Société des Assurances Automobile du Québec, Institut National de la Santé Publique du Québec,...). La méthode est le fruit des recherches et de l'expérience de violette Naville-Morin, sociologue et chef de travaux à l'Ecole de Hautes Etudes en Sciences Sociales à Paris (EHESS) et de Lise Chartier, chercheur à la Chaire de relations publiques et communications marketing de l'UQAM. L'ouvrage se veut accessible et vise à permettre l'apprentissage des bases méthodologiques de l'analyse de contenu. C'est avant tout un outil pratique destiné à des étudiants ou des professionnels. Le chercheur voulant développer une posture critique avec cette méthode devra évaluer l'outil au regard de son propre cadre épistémologique. Autre point notable, si Christian Leray nous explique comment faire de l'analyse de presse avec un tableur (Excel), il nous présente également le logiciel développé et utilisé dans le Laboratoire: CLIP (Compilation logique de l'information et de la partialité). Ce logiciel est d'ailleurs rendu accessible pour les recherches d'étudiants. Il a ainsi déjà permis à des étudiants européens, africains ou américains de travailler leurs thèses ou leurs mémoires. Le lecteur est guidé tout au long des dix chapitres de ce livre pour qu'il puisse construire et s'approprier progressivement une méthodologie éprouvée, depuis la constitution d'une grille d'analyse et du corpus jusqu'au traitement des données et l'analyse des résultats. Des exemples concrets et des cas sont présentés pour permettre au lecteur de comprendre le vocabulaire général de l'analyse de contenu ainsi que celui propre à la méthode Morin-Chartier. Ils l'aideront également dans leur appropriation et la mise en application de la méthode. Le type d'analyse de contenu favorisé ici est marqué par l'analyse de presse. C'est une méthode qui, bien qu'elle puisse servir à atteindre d'autres objectifs, prend tout son sens dans l'analyse de la couverture médiatique d'un sujet. L'analyste pourra ainsi dépasser toute forme d'a priori et évaluer avec une certaine finesse l'orientation des médias dans le traitement d'un événement, d'un débat. 